\title{
Lymph vessels: the forgotten second circulation in health and disease
}

\author{
Lukasz A. Adamczyk ${ }^{1}$ - Kristiana Gordon ${ }^{2}$ - Ivana Kholová ${ }^{3} \cdot$ Lorine B. Meijer-Jorna $^{4}$. \\ Niklas Telinius $^{5}$ • Patrick J. Gallagher ${ }^{6}$ - Allard C. van der Wal ${ }^{7}$. Ulrik Baandrup ${ }^{8}$
}

Received: 31 December 2015 /Revised: 6 April 2016/Accepted: 18 April 2016/Published online: 12 May 2016

(C) The Author(s) 2016. This article is published with open access at Springerlink.com

\begin{abstract}
The lymphatic circulation is still a somewhat forgotten part of the circulatory system. Despite this, novel insights in lymph angiogenesis in health and disease, application of immune markers for lymphatic growth and differentiation and also the introduction of new imaging techniques to visualize the lymphatic circulation have improved our understanding of lymphatic function in both health and disease, especially in the last decade. These achievements yield better understanding of the various manifestations of lymph oedemas and malformations, and also the patterns of lymphovascular spread of cancers. Immune markers that recognize lymphatic endothelium antigens, such as podoplanin, LYVE-1 and Prox1 , can be successfully applied in diagnostic pathology and
\end{abstract}

Electronic supplementary material The online version of this article (doi:10.1007/s00428-016-1945-6) contains supplementary material, which is available to authorized users.

Allard C. van der Wal

a.c.vanderwal@amc.uva.nl

1 North Bristol NHS Trust, Bristol, UK

2 St George's Hospital, London, UK

3 Pathology, Fimlab Laboratories, Tampere University Hospital, Tampere, Finland

4 Noordwest Ziekenhuisgroep, Alkmaar, The Netherlands

5 Aarhus University, Aarhus, Denmark

6 Bristol University, Bristol, UK

7 Department of Pathology, Academic Medical Centre, Amsterdam, The Netherlands

8 Vendsyssel Hospital, Aalborg University, Aalborg, Denmark have revealed (at least partial) lymphatic differentiation in many types of vascular lesions.

Keywords Lymph vessels · Vascular pathology · Metastasis · Atherosclerosis · Angiogenesis · Vascular malformation · Immunohistochemistry $\cdot$ Genetics $\cdot$ Circulation .

Lymphedema

\section{Introduction}

A most important discovery of anatomy and physiology was Harvey's description of the circulation of blood and a new understanding of the function of the heart in 1628. However, the full meaning of this ingenious research was first complete with the recognition of the lymphatic vasculature in the middle of the 17th century. At last, the Galenic teaching could be rejected. However, the lymphatic circulation is still a somewhat forgotten part of the circulatory system, since most research interest is devoted to the blood vessels and related diseases such as atherosclerosis and thrombosis. Nevertheless, our understanding of its function and clinical importance in both health and disease is improving, especially in the last decade. The introduction of new imaging techniques to visualize detailed anatomy and physiology of the lymphatic circulation yields a better understanding of the various manifestations of oedemas and the patterns of lymphovascular spread of cancers. New immuno markers recognize growth factors and differentiation antigens that are specific for lymphatic endothelial cells which expands the knowledge on lymphangiogenesis in chronic inflammatory diseases and also in malignant tumours. Some of these immune markers are now applied in diagnostic pathology and reveal lymphatic differentiation in an increasing number of vascular tumours or tumour-like conditions. 


\section{Lymph vessels under normal conditions}

\section{Macroscopic anatomy and organization}

The lymphatic vasculature is a drainage network that begins in the interstitial spaces and ends in the great veins of the neck or thorax. The lymphatic vessels can be divided into three different types: initial lymphatics, pre-collectors and collecting lymphatics. The initial lymphatics are non-contracting vessels composed of a single layer of lymphatic endothelial cells attached to interstitial collagen fibres by anchoring filaments and surrounded by a discontinuous basement membrane, without pericytes [1]. Fluid entry is by absorption and depends on a pressure gradient favouring fluid movement from interstitium into the lymphatics. Further downstream, the lymph reaches the pre-collectors, which contain valves and sparse smooth muscle cell coverage. The pre-collectors connect the absorbing initial lymphatics to the contractile collecting lymphatic vessels, which have smooth muscle cells (SMCs). Unidirectional valves divide the collecting vessels into segments called lymphangions. These lymphangions contract spontaneously and act as pumping units and are responsible for propulsion of lymph (Fig. 1). The vessel wall is divided into three layers, tunica intima, media and adventitia, albeit less well organized than in blood vessels. Their smooth muscle cell content increases proximally. The collecting lymphatics pump the lymph further centrally, which, after passing through the regional lymph nodes, reaches the thoracic duct or the right lymphatic trunk.

The human thoracic duct is comprised of SMCs arranged in bundles with no distinct longitudinal or circumferential orientation [2]. Ultrastructurally lymphatic SMCs resemble vascular SMCs with a complete basal lamina, caveolae in regular alternation with membrane-associated dense bands, cytoplasmic dense bodies and thick $(15 \mathrm{~nm})$ as well as intermediate
$(10 \mathrm{~nm})$ and thin $(5 \mathrm{~nm})$ filaments [2]. Interstitial Cajal-like cells have been reported in both human and sheep lymphatic vessels based on morphology and immunohistochemistry [2, 3]. Whether these cells have the role as pacemaker cells, like the interstitial cells of Cajal in the gastrointestinal tract, is not yet known.

\section{Physiological roles}

The lymphatic system has three cardinal functions: (1) maintenance of interstitial fluid balance, (2) immune surveillance and (3) absorption of fat. All ingested fat, except the small amount of short fatty acids present in a normal diet, is taken up by the intestinal lymphatics and transported to the venous circulation. The lymphatic vessels play an important role in host defence by carrying antigens and immune cells from the tissues. It is therefore not surprising that lymphedema patients have an increased risk and severity of skin infections.

\section{Interstitial fluid balance}

As blood passes through the capillaries, there is a continuous fluid filtration into the interstitial space. The extravasation of fluid is dictated by the Starling forces and accumulates to a total of 81 of fluid during $24 \mathrm{~h}$ [4]. The only way by which the fluid can be returned to the blood circulation is via the lymphatic vasculature. Traditionally, venous reabsorption was thought to play the most important role, absorbing up to $90 \%$ of the fluid, but there is now comprehensive evidence that venous reabsorption is non-existent in most vascular beds during steady state conditions [5]. Oedema occurs when there is a mismatch between microvascular filtration and lymphatic removal and can thus be caused by an increase in filtration, reduced lymphatic removal or both.
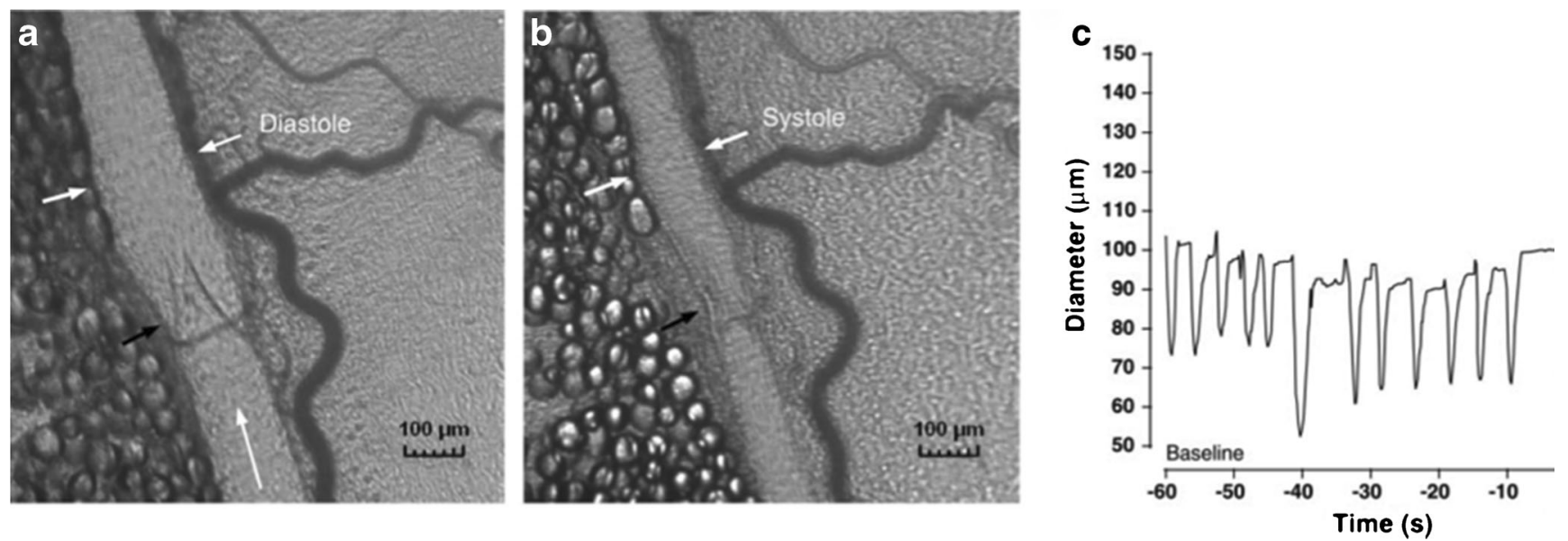

Fig. 1 Intravital microscopy photographs showing a lymphatic vessel in diastole (a) and systole (b). The white arrows mark the vessel wall and the black arrow marks the valve. The corresponding diameter changes are

depicted in (c). Adapted with permission from Am J Physiol Heart Circ Physiol 2007;293:H709-18 
Lymphatic failure or inadequacy is therefore present in all chronic oedemas.

\section{Lymph transport}

Lymph transport is the result of a combination of intrinsic and extrinsic factors. Arterial pulsation, skeletal muscle contraction and respiration are examples of extrinsic factors, which cause transient tissue deformations leading to compression and expansion of the initial lymphatics. Intrinsic spontaneous contractions are generated in the lymphangions. Their contraction cycle is very similar to a cardiac ventricle. However, the heart has two pumping chambers coupled in parallel, whereas the lymphatic vessels have numerous pumping chambers coupled in series. Systolic pressure generated by the spontaneous contractions in humans can reach up to $100 \mathrm{mmHg}$, and several studies show averages of around $40-60 \mathrm{mmHg}$ in arms and legs in humans, [6, 7]. The contractions are influenced by many different stimuli: humoral, neuronal, pressure, temperature and shear stress $[8,9]$. Both increases in preload and afterload lead to changes in contractility [10]. Similar to arteries, there is flow-mediated NO production and myogenic constrictions as a response to increased stretch $[11,12]$. Lymphatic vessels show reactivity, either inhibitory or stimulatory to a vast panel of vasoactive substances such as substance $\mathrm{P}$, noradrenaline, histamine, endothelin and prostaglandins [13-15]. Despite extensive evidence of a lymphatic innervation, most consistently described as sympathetic, the exact role of the nerve supply remains unclear $[16,17]$.

\section{Key points:}

- Lymphatic vessels are widely distributed throughout the body. They can be divided into absorbing, non-contracting initial lymphatics and contractile collecting lymphatics.

- Lymph flow is not a passive process, but results from spontaneous contractions generated in functional units called lymphangions

\section{In vivo imaging of lymphatic vessels}

\section{Lymphoscintigraphy}

Dysfunction of the lymphatics leads to oedema. Diagnosis of the specific type of oedema is based on the history and clinical findings, eventually supported by techniques available to assess lymphatic function in a patient. Lymphoscintigraphy is the current gold standard investigation to determine whether limb swelling is the result of lymphatic dysfunction (Fig. 2) [18].
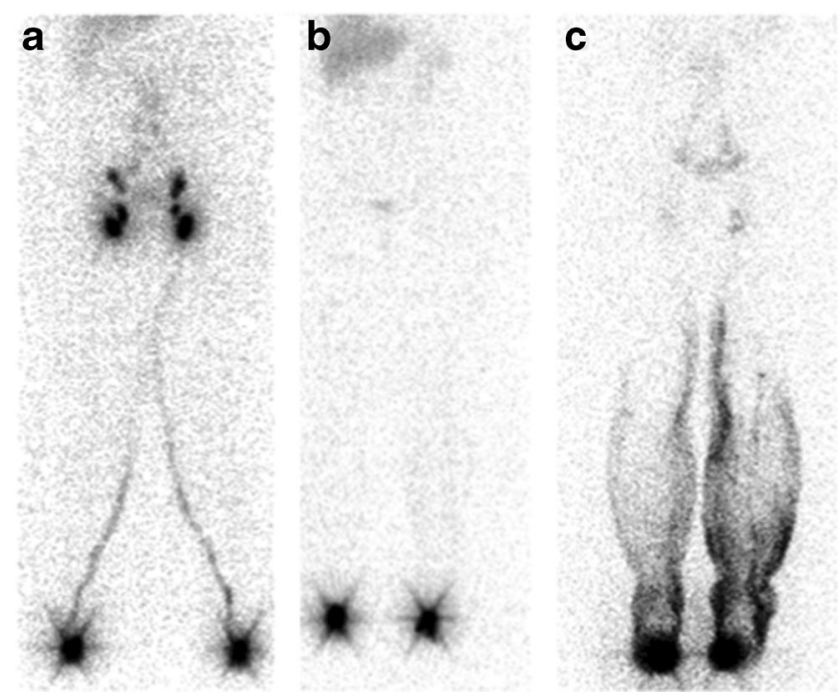

Fig. 2 Lymphoscintigraphy of a healthy subject (a). Depots at the injection sites on the feet and lymphatic vessels draining the injections sites can be seen as well as the lymph nodes in the groin that the vessels lead to. Lymphatic failure in a patient with Milroy's disease (b). No lymphatic vessels or uptake in the groin can be seen. Lymphoscintigraphy of a patient with lymphedema distichiasis syndrome (c). There is dermal reflux of lymph fluid in the lower legs. No clear vessels can be seen and there is reduced uptake in the lymph nodes in the groin

\section{Magnetic resonance lymphangiography}

Magnetic resonance lymphangiography provides superior visualization of the lymphatic vessels, which allows better description of vessel morphology, but is inferior to scintigraphy in the detection of lymph nodes [19].

\section{Near infrared fluorescence imaging}

Near infrared fluorescence imaging or indocyanine green lymphography is a relatively new technique used to visualize superficial lymphatic vessels [20,21]. The technique is based on injection of a fluorescent dye that is absorbed by the lymphatic vessels. The technique is used routinely to identify suitable vessels for lymphatic-venous anastomosis surgery [22]. It is furthermore used by some to stage lymphedema [23]. The technique will probably play a key role in clinical practice and research in the future.

\section{Key points:}

- Lymphoscintigraphy is the gold standard for investigating the lymphatic vasculature in humans. The techniques allow quantification of lymph transport and visualization of the major lymphatic vessels.

- Magnetic resonance lymphangiography and near infrared fluorescence imaging is emerging as new techniques due to superior spatial and temporal resolution. 


\section{Primary lymphedema}

Primary lymphedema is caused by a failure of the development of the lymphatic system (lymphangiogenesis) leading to either structural or functional abnormalities that impair maintenance of interstitial fluid balance. Mutations within several genes involved in the process of lymphatic development are now known to cause different primary lymphedema phenotypes. Primary lymphedema is not one disease, but the presenting feature of several distinct clinical entities.

Previously, primary lymphedema was classified based on age of onset: congenital, praecox (pubertal onset) and tarda (onset after 35 years). The discovery of causal genes has changed the diagnostic approach, which is now based on clinical phenotyping and genotyping in addition to age of onset of swelling (Fig. 3) [24]. Primary lymphedema can be divided into five different categories: (1) lymphedema associated with syndromic disorders (e.g. Turner or Noonan syndrome); (2) localized or generalized lymphedema with systemic/visceral lymphatic abnormalities; (3) lymphedema in association with disturbed growth and/or cutaneous/vascular anomalies (e.g. Proteus syndrome); (4) congenital lymphedema (e.g. Milroy disease); (5) late-onset primary lymphedema. A number of disease subtypes within each category have an associated causal gene. Despite recent advances in genetics, mutations in causal genes have only been detected in approximately one third of all patients with primary lymphedema [25]. For an overview over the causal genes and the resulting phenotype, see Appendix.

The identification of the genetic cause of a patient's primary lymphedema provides a molecular diagnostic test for a number of subtypes. Nine causal genes have been discovered so far [26]. Patients and families benefit hugely from the diagnosis as it allows the clinician to confidently predict the clinical prognosis and offer screening for family members. The identification of new pathogenic genes will increase understanding of the aetiopathogenesis of lymphatic disease. In time, this may allow for the development of improved therapeutic interventions. For example, gene therapy may become a feasible treatment strategy for cases of primary lymphedema.

\section{Secondary lymphedema}

Secondary lymphedema is the most common form of lymphedema. Globally, the parasite infection filariasis is the most common cause with over 100 million people affected. In the industrialized world, cancer-related lymphedema is the most common cause, either as a direct consequence of the cancer or the treatment.
Key points:

- Primary lymphedema is caused by a failure of the development of the lymphatic system whereas secondary lymphedema is the result of an external stimulus, e.g. parasitic or cancer (metastasis or induced by treatment).

- Advance in genetics have so far identified nine causal genes of primary lymphedema and has helped refine the classification of primary lymphedema, which now is based on clinical genotyping and phenotyping.

\section{Microscopic imaging of lymphatic vessels and histopathology of lymphatics}

Morphologically, it is difficult to distinguish lymphatic channels from venules or capillaries. In the era before development of lymph endothelial-specific antibodies, a variety of techniques was used to visualize lymphatic vessels, which included injection techniques with India ink or Evans Blue, hydrogen peroxide techniques $[27,28]$ and the enzyme histochemical detection of 5'nucleotidase [29].

\section{Immunohistochemical markers for lymphatic endothelium}

Pan-endothelial markers such as CD31, CD34, von Willebrand factor (vWF), lectins, thrombomodulin, endoglin, and Fli-1 are expressed in all endothelial cells, including lymphatic endothelium CD31(PECAM, platelet adhesion molecule) which is considered to be the most sensitive and specific pan-endothelial marker but is also reactive with platelets and subpopulations of $\mathrm{T}$ lymphocytes [30, 31]. Lymphatic endothelial markers are expressed in lymphatic endothelium, but not in blood vessel endothelium. Table 1 summarizes the expression patterns of currently applied lymphendothelialspecific antibodies, which can now be applied on paraffin-embedded tissues.

Podoplanin is a mucin-type transmembrane glycoprotein originally described on rat kidney podocytes [32]. In the literature, it appears also under the names AGGRUS, gp36, oncofetal antigen M2A and T1A-2 [33]. Apart from lymphatic endothelial cells, it is also expressed by other cells types including tumour cells [33]. D2-40 is the most common mouse monoclonal antibody and NZ-1 the most commonly used rat monoclonal antibody against podoplanin [33, 34].

Prox-1 (homolog of the Drosophila melanogaster homeobox gene prospero) is a nuclear transcription factor, which plays a crucial role in the development of the lymphatic system. It is a master control gene introducing the expression of other lymphatic markers [35]. Immunoreactivity of 


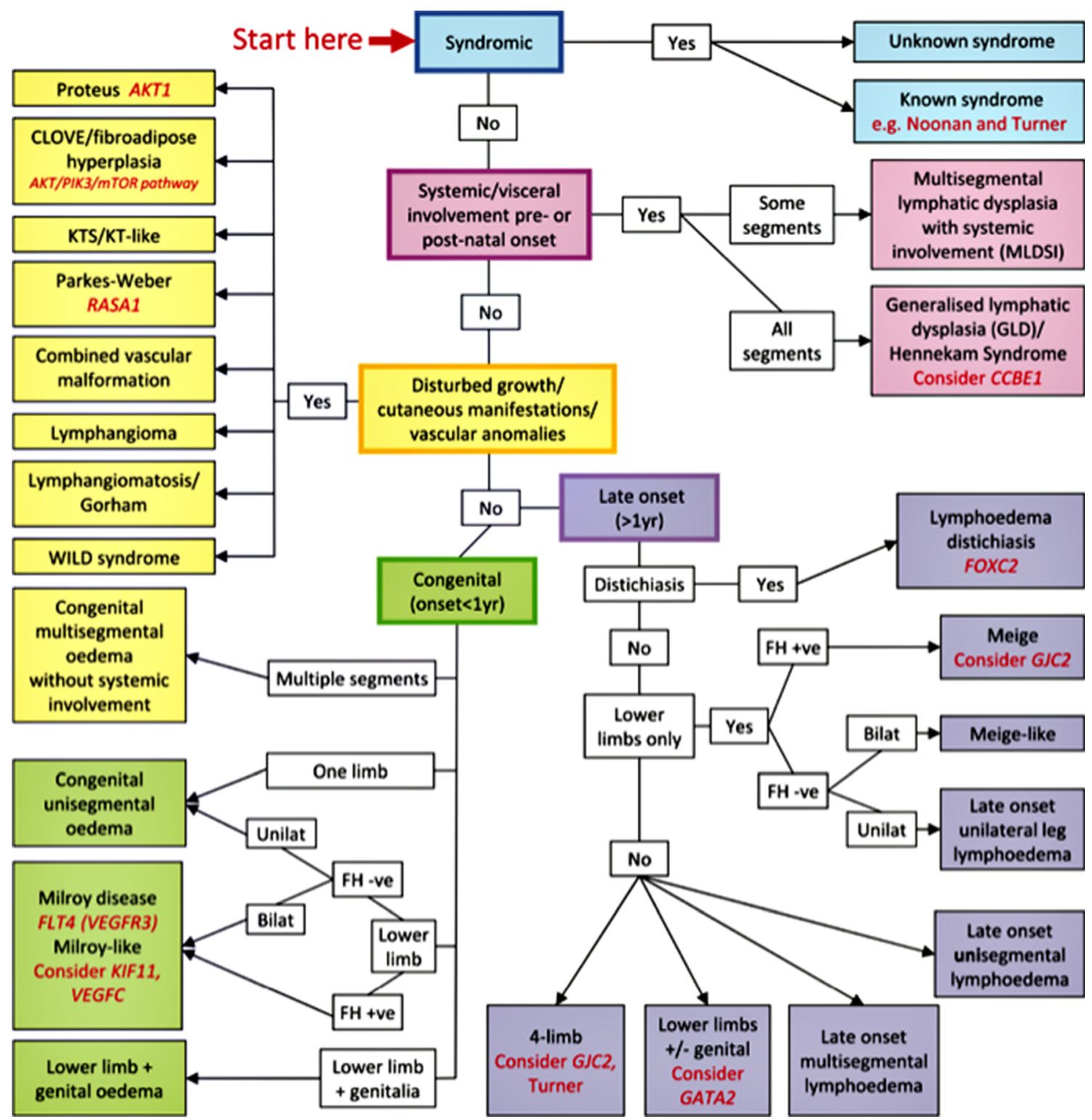

Fig. 3 Classification pathway for primary lymphedema. The pathway provides an overview over the different primary lymphedemas, clinical features and causal genes. $F h=$ family history. Adapted with permission from Clinical Genetics 2013;84:303-314

Prox-1 antibody is nuclear, which is in contrast to the other lymphatic markers. Expression has been observed also in lens, heart, liver, pancreas and nervous system [36]. In colonic carcinomas, expression of Prox-1 in stem/progenitor
Table 1 Expression of immunohistochemical markers for lymphatic endothelium along the vascular bed

\begin{tabular}{llllll}
\hline Lymphatic markers & & Podoplanin & LYVE-1 & Prox-1 & VEGFR-3 \\
\hline Lymphatic vessels & Capillary & ++ & ++ & ++ & ++ \\
& Collecting vessel & ++ & + & + & $+/++$ \\
Blood vessels & Artery & - & - & - & - \\
& Capillary & - & - & - & + \\
& Vein & + & - & - & - \\
Hepatic sinus & + & + & - & + & \\
Embryonic development & + /++ & $+/+$ & ++ & $+/++$ & \\
Postnatal development & ++ & ++ & ++ & ++ & \\
\hline
\end{tabular}

- :no expression; +:weak expression; ++: strong expression; +/++: variable expression 
cells is responsible for autophagy-dependent survival of metastases [37, 38].

LYVE-1 is an integral membrane glycoprotein also known as lymphatic vessel endothelial hyaluronan receptor 1. It is an important component of extracellular matrix and a key molecule in cell migration during inflammation, wound healing and in tumorogenesis [39]. In addition to the cytoplasm of lymphatic endothelium, it is expressed in liver and spleen sinusoid endothelium and activated macrophages [40].

Vascular endothelial growth factor receptor-3 (VEGFR-3, also known as FLT4) is a membrane-anchored tyrosine kinase binding VEGF-C and VEGF-D involved in lymphangiogenesis [41]. VEGFR-3 was initially widely applied as a purely lymphatic marker, but later studies showed its reactivity with blood vessel endothelium, myoepithelial cells and cells of some non-endothelial tumours [42]. And also, other markers such as neuropilin-2, FOXC2, CCL21, D6 and aquaporin-1 appear to be not fully specific for lymphatic endothelium [43].

For studies on the (micro)vasculature in pathological conditions, we recommend the use of a panel of three endothelial antibodies, which consists of one pan-endothelial marker and two different lymphatic endothelial-specific antibodies, in order to avoid false positivity/negativity of staining results [44].

Key points

- CD31 is the most sensitive and specific pan-endothelial marker.

- Most important specific lymphatic endothelium markers are podoplanin (D2-40), Prox-1, and LYVE-1.

- The use of the panel of one pan endothelial marker and two lymphatic markers is recommended for proper identification of lymphatic vessels.

\section{Lymphatic vessels: inflammation}

Studies on lymph vessels in mouse models of inflammation and inflamed human tissues have shown that acute inflammatory reactions and chronic inflammatory diseases are accompanied by both the growth of new lymphatic vessels (lymphangiogenesis) and the expansion of preexisting lymphatic vessels (lymphatic hyperplasia). These mechanisms occur not only in the inflamed tissues but also in draining lymph nodes. Lymphangiogenesis, activation of lymph vessels and enhanced lymphatic drainage may have modulating effects on immune responses and the activity of the inflammatory process which is now under intense investigation [45]. This has been profoundly studied in arthritis, inflammatory bowel disease and dermatitis [46-49].

\section{Lymphatic vessels: transplantation}

Interestingly, chronic renal transplant rejection-associated lymphatic vessel proliferation represents inflammationassociated de novo lymphangiogenesis [50]. Also, chronic cardiac allograft lymphangiogenesis is inflammation-driven and the lymph vessels are important for migration of donor and host antigen-presenting cells. There are indeed indications that suppression of lymphangiogenesis improves graft survival, for example, through blocking of the dendritic cell chemokine CCL21 in both heart and renal graft rejection [51, 52].

\section{Lymphatic vessels: atherosclerosis, lipid metabolism, obesity and hypertension}

Lymphangiogenesis in intimal plaques and adjacent media has been reported in atherosclerotic human coronary arteries, where both the calcified and the cholesterol-rich types of plaques are involved [44]. Plaque inflammation is an important denominator in the formation of "high risk plaques" which are prone to thrombotic complications, and such an increase in lymph vessels could play a role in further recruitment of inflammatory cell into the plaque tissue. Moreover, lymphatic vessels are involved in artery wall lipoprotein metabolism and cholesterol plasma levels [53, 54]. Also, the degenerative fibrocalcified heart valves of the elderly population, which frequently display some low-grade inflammatory activity with similar phenotypic features as in atherosclerosis, appear to be prone to lymphatic growth. Aortic plaqueassociated lymphatic vessel growth has also been observed in experimental mouse models of atherosclerosis [44]. Altogether, an inflammatory component in these diseases is often associated with tissue instability and related cardiovascular risk, which implies that such knowledge on lymphatic vessels can be instrumental for assessment of a potential use of antilymphangiogenic therapeutic strategies in atherosclerosisrelated diseases.

\section{Lymphatic differentiation in tumours and tumour-like lesions}

\section{Current classification}

In practice (clinically and also pathologically) it can be difficult to determine whether a given vascular lesion is in fact a true tumour, a developmental malformation or a reactive process composed of either blood vessels, lymph vessels or both. Consistent with this, there is variability in nomenclature and sometimes misleading terminology in the literature, which may hamper appropriate evaluation and management of patients. The classification of the International Society for the Study of Vascular Anomalies (ISSVA), which stratifies the 
vascular anomalies into malformations and proliferative vascular lesions, has recently been updated in order to attempt a uniform state of the art and includes the main lymphatic tumours and malformations, involvement in dysmorphic syndromes and genetic backgrounds [55]. The online version is also available at www.issva.org. A previous version of this classification system has been validated recently in a large referral centre for vascular anomalies [56]. It has proven to be useful, also for clinical pathologists, albeit dependent on the adequacy of clinical information, preoperative imaging techniques and the use of immunohistochemistry for GLUT1 (infantile haemangiomas), specific lymphatic endothelium antibodies, and the vascular smooth muscle antibody SMA-1( vascular integrity and maturation).

Lymphatic malformations Lymphatic malformations (LMs) are sponge-like collections of abnormal and cystically dilated lymph vessels filled with lymph fluid. In the past, most lymphatic lesions were designated as lymphangiomas', but in the current classification, they now are labelled as 'lymphatic malformations' because of the usually congenital nature, slowly progressive growth over time and composition of malformed dilated lymphatic vessels [55, 57]. Based on the size of vessel lumen, LMs are classified as microcystic (previously termed lymphangioma circumscriptum), macrocystic (previously termed cystic hygromas) or mixed subtypes [58]. They can be located superficially or deep and occur (multi) focal or diffuse. Sudden enlargement may occur during infection or spontaneous bleeding within the cysts. Many lesions are congenital, although not always visible at birth, but small lesions may develop also in response to trauma or infection. Lymphangiogenic growth factors, such as VEGF-C and VEGFR-3, are upregulated in LMs, but the precise role of these factors in their development is not clear [59]. In histopathology, an LM reveals a convolute of dilated lymph vessels with incomplete medial layers of one to multilayered smooth muscle cells and can be associated with nodular lymphoid tissue (Fig. 4a-c). Endothelial cell lining is flat but obtains a hobnail-like appearance, in cases with trauma, haemorrhage or chronic inflammation (Fig. 1). Endothelium stains positively with several lymphatic specific antibodies [60], but staining intensity can be markedly reduced in the flat endothelium of
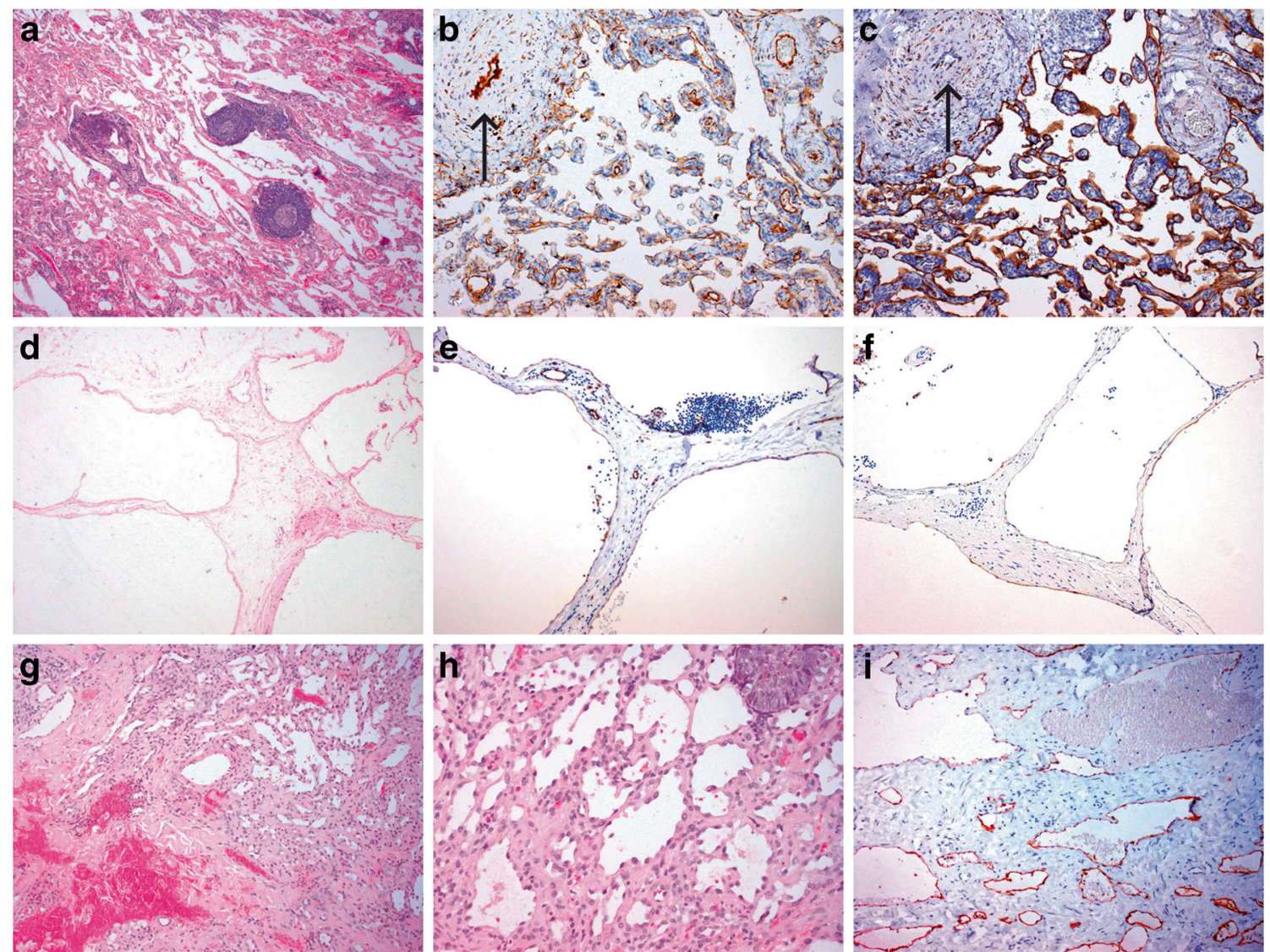

Fig. 4 Lymphatic malformation with intralesional formation of lymph follicles (a-c); Haematoxylin and eosin stain (HE) (a); anti-CD31 immunostain (b); anti-D2-40 immunostain of endothelium (c); macrocystic lymphatic malformation (d-e): HE (d); CD31, low intensity to absent

immunostaining with D2-40 antibody of endothelial cells at cystic structures (e) (compared with D2-140 immunostain in (f)); Traumatic changes and haemorrhage in LM $(\mathbf{g}-\mathbf{h})$, with hobnail-type endothelium in (h). D240 immunostaining of microvessels (i) 
cystically dilated lymph channels (Fig. 4d-k). Traumatic changes in lymphatic malformations frequently cause haemorrhage and thrombosis, especially in combined lymphaticovenous malformations. Therefore, presence of erythrocytes in vessel lumina does not rule out a diagnosis of a lymphatic lesion. Additional hamartomatous tissue components such as fat, nerve bundles or of reactive microvascular proliferations, which are frequently found in congenital malformations of blood vessels, are not a feature of pure lymphatic malformations [61, 62].

\section{Vascular tumours with lymphatic differentiation}

The use of monoclonal antibodies specific for lymphatic endothelium has revealed lymphatic endothelial differentiation, at least to some extent, in a still increasing list of vascular tumours that were initially considered to be composed of blood vessels only (Table 2). However, in many of these lesions, the patterns of immunostaining vary when different lymphatic antibodies are applied (see for example Fig. 5). Therefore, it is recommended to use two different lymphatic antibodies; salient examples of such 'newly' described lymphatic lesions are as follows:

1. Spindle cell haemangioma. First reported in 1986 as lowgrade malignant and termed spindle cell hemangioendotheliomas [63]. It is now considered as a benign type of lesion with clinical and biological features more reminiscent of congenital vascular malformations.
A recent study of 12 cases of spindle cell haemangiomas showed a positive endothelial lining with coexpression of pan-endothelial and lymphatic antibodies, suggesting its lymphatic origin [64].

2. Multiple lymphangioendotheliomatosis. An extremely rare disease in infancy associated with thrombocytopenia [65]. Patients present with hundreds of congenital vascular lesions in the skin, which have the characteristics of both blood vascular and lymphatic vessels (Fig. 5). Similar lesions involve the gastrointestinal (GI) tract causing severe GI tract bleeding.

3. Kaposiform hemangioendothelioma (KHE) of childhood. This is a vascular tumour with a locally aggressive behaviour and often complicated by severe coagulopathies (in the most serious form, the Kasabach-Merritt syndrome) [66]. However, these coagulation abnormalities are not unique for KHE but have been noticed also in other vascular tumours and malformations [56]. Spindle cells of this tumour coexpress blood and lymphovascular markers [67].

4. Kaposi sarcomas (KS). Also coexpress blood vascular and lymphatic markers in all the histopathological variants. These markers are useful in the recognition of KS, since there is a variation in morphology of the lesions varying from scant multicentric, small dilated microvessels to solid spindle cell proliferations; others present as polypoid tumour masses mimicking pyogenic granuloma or even closely resembling haemangiomas. Recent studies have shown that the KS herpes virus can
Table 2 Tumours and tumourlike lesions with at least partial lymphatic differentiation

\begin{tabular}{|c|c|}
\hline Name & Biological behavior according to ISSVA ${ }^{\text {a }} 2015$ [55] \\
\hline $\begin{array}{l}\text { Primary lymphoedema/ } \\
\text { lymphatic malformation }\end{array}$ & $\begin{array}{l}\text { Congenital malformation. Isolated or in combination with other vascular or } \\
\text { nonvascular malformations or genetic syndromes }\end{array}$ \\
\hline Tufted angioma & Benign tumor of skin. Partial lymphatic differentiation ${ }^{\mathrm{b}}$ \\
\hline Spindle cell angioma & $\begin{array}{l}\text { Provisionally unclassified. Probably vascular malformation with partial } \\
\text { lymphatic differentiation }\end{array}$ \\
\hline Verrucous angioma & $\begin{array}{l}\text { Provisionally unclassified; probably congenital malformation with partial } \\
\text { lymphatic }\end{array}$ \\
\hline Angiokeratoma & $\begin{array}{l}\text { Provisionally unclassified vascular anomaly. Partial lymphatic } \\
\text { differentiation }\end{array}$ \\
\hline $\mathrm{dMLT} / \mathrm{CAT}^{\mathrm{c}}$ & Provisionally unclassified lesion. \\
\hline $\begin{array}{l}\text { Kaposiform } \\
\text { hemangioendothelioma }\end{array}$ & $\begin{array}{l}\text { Locally aggressive tumor. Extends into deep tissues; resembles tufted } \\
\text { angioma }\end{array}$ \\
\hline PILA $^{\mathrm{d}}$ & Borderline malignant tumour \\
\hline Kaposi sarcoma & Borderline malignant tumour \\
\hline Lymphangiosarcoma & Malignant. Variable expression patterns with lymphatic markers \\
\hline Kaposiform lymphangiomatosis & Provisionally unclassified vascular lesion \\
\hline
\end{tabular}




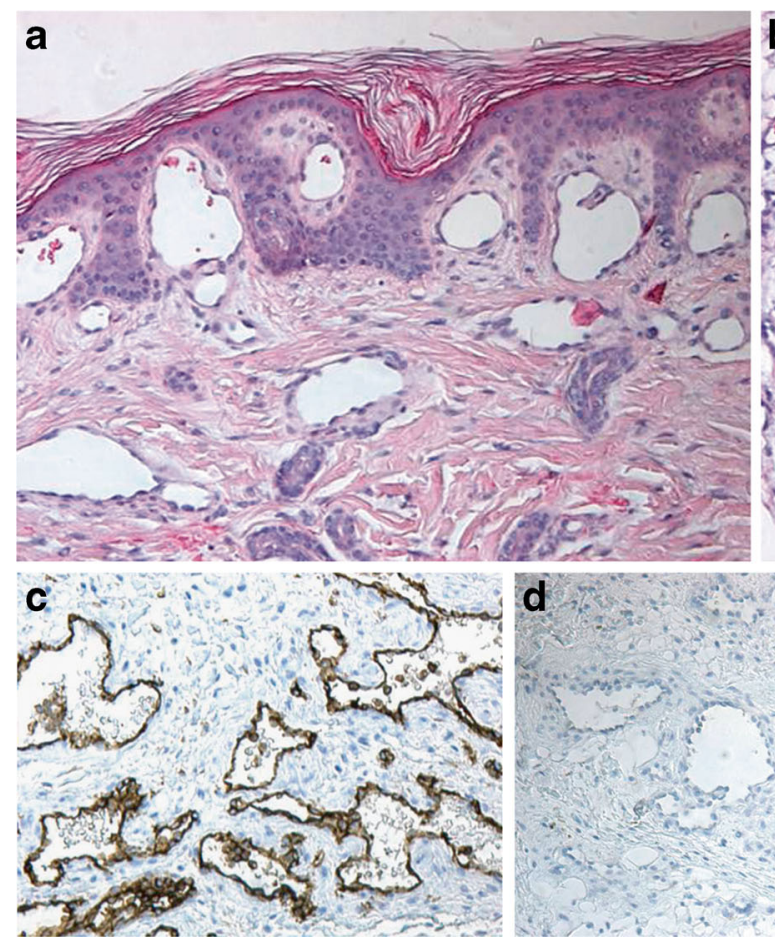

Fig. 5 Multiple lymphangioendotheliomatosis. Skin surface with subepidermal dilated thin-walled vessels (HE) (a); deep-seated atypical vessels in subcutis, partially filled with erythrocytes (HE) (b); CD31

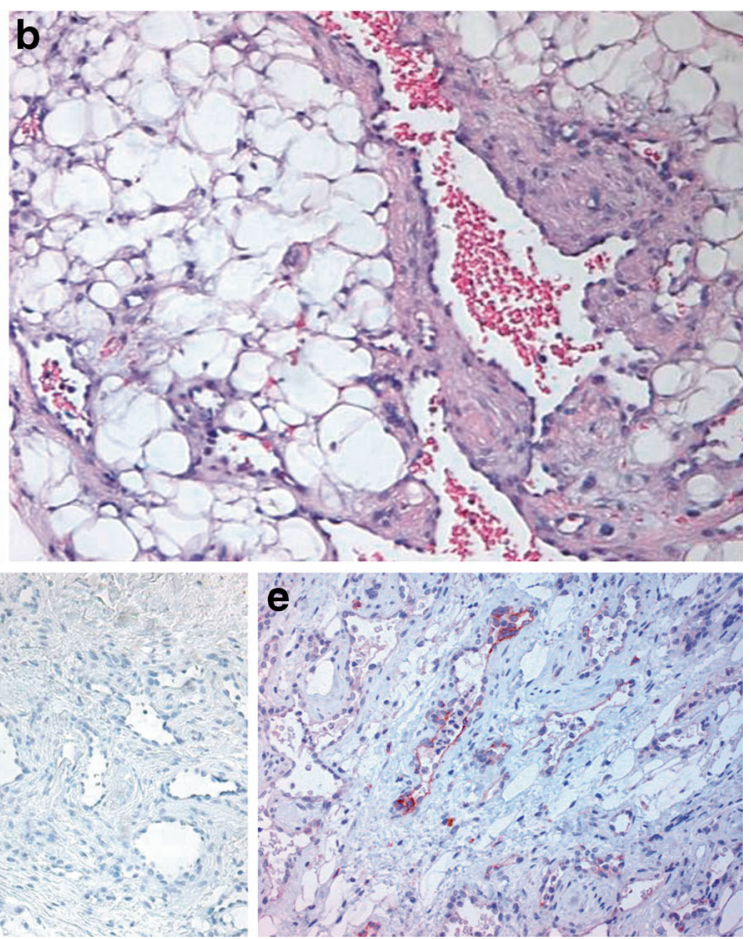

immunostain of atypical microvessels (c); absent D2-40 immunostaining (d); focal LYVE-1 immunostaining of microvessels (e)

endothelium showed broadest immunoreactivity with these markers. This implies that at least histopathologically, they should be defined as lymphangiosarcomas.

\section{Lymphovascular invasion: patterns and diagnosis} entiation in a large subset of lesions that were traditionally considered to be true hemangiosarcomas (both the solitary and the radiation induced types of tumours). In a recent study of 49 angiosarcomas by Mankey et al. [70], more than half of the number of tumours showed immunopositivity with at least two out of three applied lymphatic antibodies (D2-40, Prox 1, LYVE-1). Especially, tumours with intratumoral aggregates of lymphoid tissue and prominent hobnail appearance of

\footnotetext{
Key points

- Many lesions that were previously designated as 'lymphangiomas' are in fact lymphatic malformations, being mostly congenital in nature

- Specific lymphatic endothelium antibodies identify (partial) lymphatic differentiation in a still increasing number of vascular tumours

- Occurrence of blood-filled spaces, haemorrhages or hobnail appearance of endothelium does not rule out the diagnosis of a lymphatic lesion
}

The importance of vascular invasion in tumour biology was established over 100 years ago. In his classic textbook, Willis summarized the early work and described the patterns of tumour spread in autopsies on patients with a variety of disseminated cancers [71]. From the numerous recent studies on lymphatic and blood vessel invasion (LBVI) in surgically resected tumours, we have summarized reports which emphasize the importance of accurate detection of vascular invasion (Table 3). Many of these reports indicate no clear distinction between lymphatic and blood vessel invasion or do not focus on lymphatic vessels in depth. In everyday practice, the detection of lymphatic invasion (LI) alone is especially important in breast carcinoma and malignant melanoma in particular because it may influence on patient management or the choice of adjuvant chemotherapy [78, 80, 81]. 


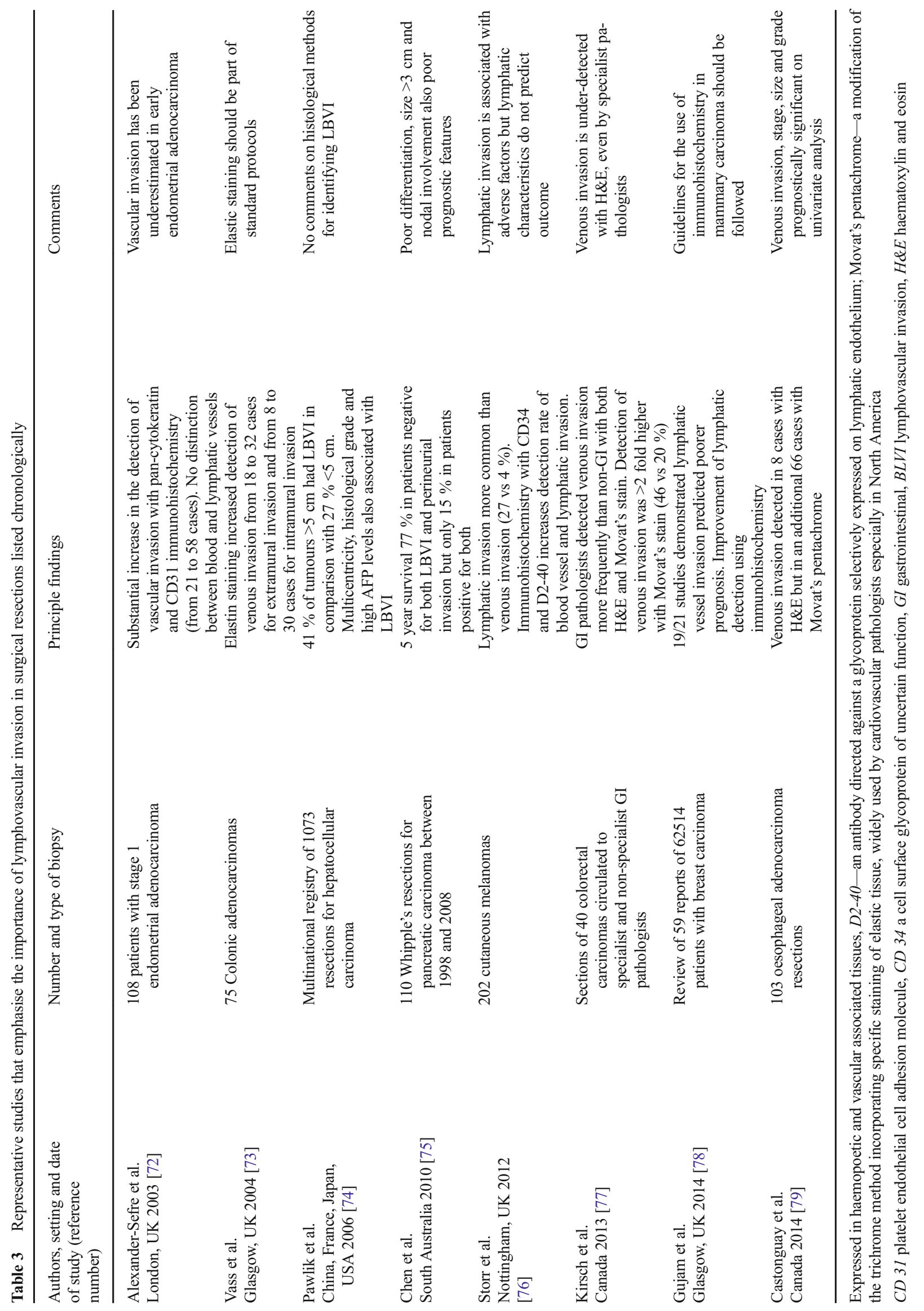




\section{Detection of lymphovascular invasion in surgical resections}

\section{Breast}

LBVI is underdetected in breast carcinoma, probably in as many as a fifth of cases. Blood vessel and lymphatic endothelial markers are helpful in detection of LBVI both within and at the edge of tumours. Invasion in vessels at the advancing tumour edge is especially important [81]. In a recent review of more than 30 reports, Gujam et al. found that blood or lymphatic vessel invasion was detected in $24 \%$ of cases on H\&E rising to $35 \%$ with immunohistochemistry [78]. Although the exact prognostic significance of vascular invasion is uncertain, its presence or absence may influence the type of chemotherapy that is used. The review emphasizes that the detection of LI is especially important in operable breast carcinomas without lymph node spread. However, some studies indicate LBVI in node-positive breast carcinoma may be prognostically valuable.

2 Oesophageal and gastric carcinomas

The incidence of oesophageal and gastric carcinomas is increasing in many countries and the 5-year survival is persistently low. In some studies of oesophageal carcinoma, venous invasion was found to reduce both disease-free survival and cancer-specific survival [82]. Recognition of any type of vascular invasion in oesophageal carcinoma is now a requirement and distinction between lymphatic and venous may be relevant [83].

In earlier studies, gastric cancer LBVI was independently related to survival and cancer recurrence [84] regardless of tumour stage or size [85]. LI is a common feature in gastric cancer but despite early suggestions of lymphatic invasion alone playing an independent prognostic role [86], this hypothesis requires further confirmation.

\section{Colorectal cancer}

The latest colorectal cancer dataset of the Royal College of Pathologists of Great Britain and Ireland incorporates assessment of intramural and extramural vascular invasion and the distinction of lymphatic and venous involvement in colorectal carcinoma [87]. Lymphatic invasion was suggested as an adverse factor for survival more than 20 years ago [88] but the current prognostic emphasis is put on extramural venous invasion. It is especially important to identify LBVI in Dukes B cancers where its status may guide decisions on adjuvant therapy [89].

Specialists in GI pathology report LBVI more frequently than do general pathologists (30 vs $9 \%$ ) but even they increase their rate of detection when elastin stains are used (Table 1) [77]. A recent study by Kojima et al. showed marked improvement of detection of LBVI including LI after agreement of set microscopic criteria after a series of questionnaires and consensus meetings between pathologists (Delphi method). Two features reaching the highest kappa value in the study were either a rim of elastin or D240 marking cells covering more than $50 \%$ circumference of a tumour cluster [90].

4 Malignant melanoma

There is currently well-documented preferential LI in cutaneous malignant melanoma. In the recent work, Rose et al. examined 246 cases of malignant melanoma and showed D2-40 marker staining increased detection rate of LI sixfold compared with routine H\&E. After statistical evaluation, LI remained an independent prognostic factor for adverse patient prognosis [80]. In a UK multicentre study, Storr et al. showed over a quarter of examined cases were positive for LI compared with only $4 \%$ of invaded blood vessels. LI correlated with mitotic rate, ulceration and Breslow thickness but statistically failed to reach independent prognostic significance [76].
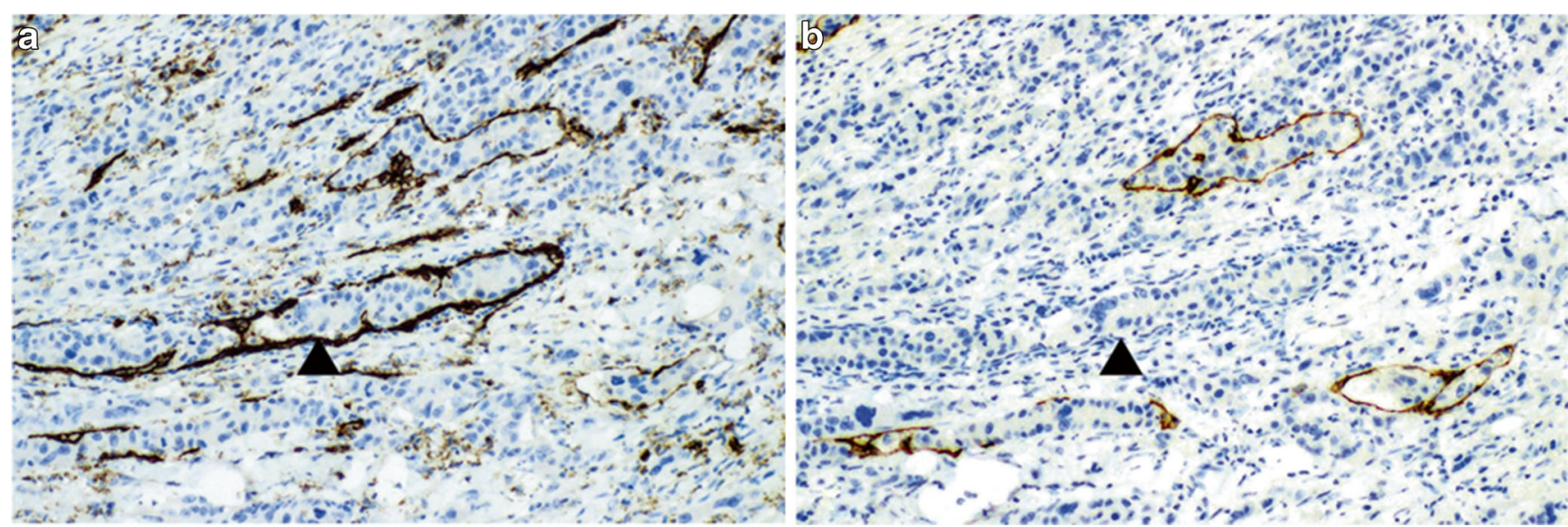

Fig. 6 Detail of tumour (melanoma) with lymphovascular invasion; CD31 immunostain showing immunoreactivity of endothelium in all microvessels (a); D2-40 immunostain showing immunoreactivity of endothelium with intravascular tumour deposit (b) 


\section{Techniques for detection of lymphatic and venous invasion}

The studies discussed above and summarized in Table $3 \mathrm{em}$ phasize the importance of LBVI and stress that it is often underdiagnosed. Three different approaches can be used to increase the accurate detection of invasion.

- Appropriate sampling of tumours and adjacent tissues

Few studies have specifically addressed dissection techniques for the enhanced detection of LBVI. The convention that malignant tumours should be sampled in three blocks is outdated and we advocate a minimum of five. Sternberg and colleagues dissected blocks perpendicular and tangential to tumours, blocks taken across the mesentery and around major blood vessels [91]. The authors found that LBVI was most often detected in perpendicular blocks but in some cases, it was only identified in the tangential blocks. Further studies of dissection techniques and the number of blocks that should be sampled would be valuable.

- "What to look for"-recognition of the particular histological features of vascular invasion

The multicentre Canadian study of Kirsch et al. described two important histological signs that suggest LBVI in colorectal carcinoma, although no distinction was made between lymphatic and blood vessels. Veins and arteries are closely related to each other but this is especially true in the bowel wall. The so-called protruding tongue sign is a rounded protrusion of carcinoma extending towards the extramural space at the tumour edge. This suggests venous invasion, especially if the deposit is close to a small artery. In the 'lone artery' or 'orphan arteriole' sign, an often elongated tumour deposit is seen next to a normal extramural artery. This, in fact, is an obliterated vein twinned with the artery [77]. Whether this also applies to lymph vessels is not known.

- Routine use of special stains, especially elastic tissue stains and vascular immunohistochemistry.

Small- and medium-sized lymphatics contain a network of elastic tissue although less in abundance than in veins. In contrast to arteries, this is not arranged as distinct internal and external lamellae but as an irregular network. Small lymphatic invasion can be identified with immunomarkers but larger vessel invasion might be indistinguishable from venous as the endothelium is obliterated by most carcinomas. Elastin can form tumour within nests of malignant cells and must not be mistaken as evidence of vascular invasion. In this context, Kojima et al. suggested that venous invasion should only be diagnosed when a tumour deposit has $50 \%$ of its circumference surrounded by elastin or D2-40 [90]. Remnants of vascular media of larger veins or lymph vessels can sometimes be visualized adjacent to tumour deposits with the use of smooth muscle actin immunostaining. Figure 6 displays intratumoral invasion of small vessels by immunostaining for CD31 and D2-40.

Representative studies that emphasize use of LVI in surgical resections are listed in Table 3. Multiple studies of gastrooesophageal and colonic carcinomas have shown that intramural and extramural LBVI is easily missed. Routine and inexpensive elastic tissue stains increase the diagnostic accuracy of both specialist and non-specialist pathologists. We suggest that they should be used routinely. In most reports, no clear distinction is made between lymphatic and blood vessel invasion. However, for certain tumours, especially melanomas, this appears to be relevant as shown in recent studies where immunohistochemistry with specific endothelial antibodies was applied to discriminate between lymphatic and blood microvasculature. These techniques at least increase the detection of venous and lymphatic invasion in mammary carcinoma and in melanoma. They should be used in selected cases, especially node-negative operable tumours.

Key points

- LI detection in breast carcinomas is especially important in patients with operable breast cancer without lymph node involvement.

- Defined criteria of vascular invasion need to be used alongside special stains to detect vascular invasion in colorectal carcinoma.

- Vascular antibodies, particularly the lymphatic marker D2-40, improve detection of LI in malignant melanoma.

\section{Compliance with ethical standards}

Conflict of interest The authors declare that they have no conflicts of interest.

Open Access This article is distributed under the terms of the Creative Commons Attribution 4.0 International License (http:// creativecommons.org/licenses/by/4.0/), which permits unrestricted use, distribution, and reproduction in any medium, provided you give appropriate credit to the original author(s) and the source, provide a link to the Creative Commons license, and indicate if changes were made.

\section{References}

1. Baluk P, Fuxe J, Hashizume H, Romano T, Lashnits E, Butz S, Vestweber D, Corada M, Molendini C, Dejana E, McDonald DM (2007) Functionally specialized junctions between endothelial cells of lymphatic vessels. J Exp Med 204:2349-2362

2. Briggs Boedtkjer D, Rumessen J, Baandrup U, Skov Mikkelsen M, Telinius N, Pilegaard H, Aalkjaer C, Hjortdal V (2013) Identification of interstitial Cajal-like cells in the human thoracic duct. Cells Tissues Organs 197:145-158

3. McCloskey KD, Hollywood MA, Thornbury KD, Ward SM, McHale NG (2002) Kit-like immunopositive cells in sheep mesenteric lymphatic vessels. Cell Tissue Res 310:77-84 
4. Renkin EM (1986) Some consequences of capillary permeability to macromolecules: starling's hypothesis reconsidered. Am J Physiol 250:H706-H710

5. Levick JR, Michel CC (2010) Microvascular fluid exchange and the revised Starling principle. Cardiovasc Res 87:198-210

6. Modi S, Stanton AWB, Svensson WE, Peters AM, Mortimer PS, Levick JR (2007) Human lymphatic pumping measured in healthy and lymphoedematous arms by lymphatic congestion lymphoscintigraphy. J Physiol Lond 583:271-285

7. Unno N, Tanaka H, Suzuki M, Yamamoto N, Mano Y, Sano M, Saito T, Konno H (2011) Influence of age and gender on human lymphatic pumping pressure in the leg. Lymphology 44:113-120

8. Dixon JB, Greiner ST, Gashev AA, Cote GL, Moore JE Jr, Zawieja DC (2006) Lymph flow, shear stress, and lymphocyte velocity in rat mesenteric prenodal lymphatics. Microcirculation 13:597-610

9. Gashev AA (2008) Lymphatic vessels: pressure- and flowdependent regulatory reactions. Ann N Y Acad Sci 1131:100-109

10. Davis MJ, Scallan JP, Wolpers JH, Muthuchamy M, Gashev AA, Zawieja DC (2012) Intrinsic increase in lymphangion muscle contractility in response to elevated afterload. Am J Physiol Heart Circ Physiol 303:H795-H808

11. Gasheva OY, Zawieja DC, Gashev AA (2006) Contraction-initiated NO-dependent lymphatic relaxation: a self-regulatory mechanism in rat thoracic duct. J Physiol Lond 575:821-832

12. Scallan JP, Wolpers JH, Davis MJ (2013) Constriction of isolated collecting lymphatic vessels in response to acute increases in downstream pressure. J Physiol Lond 591:443-459

13. Telinius N, Drewsen N, Pilegaard H, Kold-Petersen H, de Leval M, Aalkjaer C, Hjortdal V, Boedtkjer DB (2010) Human thoracic duct in vitro: diameter-tension properties, spontaneous and evoked contractile activity. Am J Physiol Heart Circ Physiol 299:H811-H818

14. Davis MJ, Lane MM, Davis AM, Durtschi D, Zawieja DC, Muthuchamy M, Gashev AA (2008) Modulation of lymphatic muscle contractility by the neuropeptide substance P. Am J Physiol Heart Circ Physiol 295:H587-H597

15. Rehal S, Blanckaert P, Roizes S, Von Der Weid P-Y (2009) Characterization of biosynthesis and modes of action of prostaglandin E2 and prostacyclin in guinea pig mesenteric lymphatic vessels. Br J Pharmacol 158:1961-1970

16. McHale NG (1990) Lymphatic innervation. Blood Vessels 27:127136

17. Telinius N, Baandrup U, Rumessen J, Pilegaard H, Hjortdal VE, Aalkjaer C, Boedtkjer DMB (2014) The human thoracic duct is functionally innervated by adrenergic nerves. Am J Physiol Heart Circ Physiol 306:H206-H213

18. Scarsbrook AF, Ganeshan A, Bradley KM (2007) Pearls and pitfalls of radionuclide imaging of the lymphatic system. Part 2: evaluation of extremity lymphoedema. Br J Radiol 80:219-226

19. Notohamiprodjo M, Weiss M, Baumeister RG, Sommer WH, Helck A, Crispin A, Reiser MF, Herrmann KA (2012) MR lymphangiography at $3.0 \mathrm{~T}$ : correlation with lymphoscintigraphy. Radiology 264:78-87

20. Sevick-Muraca EM, Sharma R, Rasmussen JC, Marshall MV, Wendt JA, Pham HQ, Bonefas E, Houston JP, Sampath L, Adams KE, Blanchard DK, Fisher RE, Chiang SB, Elledge R, Mawad ME (2008) Imaging of lymph flow in breast cancer patients after microdose administration of a near-infrared fluorophore: feasibility study. Radiology 246:734-741

21. Unno N, Inuzuka K, Suzuki M, Yamamoto N, Sagara D, Nishiyama M, Konno H (2007) Preliminary experience with a novel fluorescence lymphography using indocyanine green in patients with secondary lymphedema. J Vasc Surg 45:1016-1021

22. Chang DW, Suami H, Skoracki R (2013) A prospective analysis of 100 consecutive lymphovenous bypass cases for treatment of extremity lymphedema. Plast Reconstr Surg 132:1305-1314
23. Yamamoto T, Narushima M, Doi K, Oshima A, Ogata F, Mihara M, Koshima I, Mundinger GS (2011) Characteristic indocyanine green lymphography findings in lower extremity lymphedema: the generation of a novel lymphedema severity staging system using dermal backflow patterns. Plast Reconstr Surg 127:1979-1986

24. Connell FC, Gordon K, Brice G, Keeley V, Jeffery S, Mortimer PS, Mansour S, Ostergaard P (2013) The classification and diagnostic algorithm for primary lymphatic dysplasia: an update from 2010 to include molecular findings. Clin Genet 84:303-314

25. Mendola A, Schlögel MJ, Ghalamkarpour A, Irrthum A, Nguyen HL, Fastré E, Bygum A, van der Vleuten C, Fagerberg C, Baselga E, Quere I, Mulliken JB, Boon LM, Brouillard P, Vikkula M, Lymphedema Research Group (2013) Mutations in the VEGFR3 signaling pathway explain $36 \%$ of familial lymphedema. Mol Syndromol 4:257-266

26. Mortimer PS, Rockson SG (2014) New developments in clinical aspects of lymphatic disease. J Clin Invest 124:915-921

27. Eliskova M, Eliska O (1992) How lymph is drained away from the human papillary muscle: anatomical conditions. Cardiology 81 : 371-377

28. Parke WW, Michels NA (1963) A method for demonstrating subserous lymphatics with hydrogen peroxide. Anat Rec 146:165-171

29. Bhardwaj S, Roy H, Gruchala M, Viita H, Kholova I, Kokina I, Achen MG, Stacker SA, Hedman M, Alitalo K, Ylä-Herttuala S (2003) Angiogenic responses of vascular endothelial growth factors in periadventitial tissue. Hum Gene Ther 14:1451-1462

30. Ordóñez NG (2012) Immunohistochemical endothelial markers: a review. Adv Anat Pathol 19:281-295

31. Pusztaszeri MP, Seelentag W, Bosman FT (2006) Immunohistochemical expression of endothelial markers CD31, CD34, von Willebrand factor, and Fli-1 in normal human tissues. J Histochem Cytochem 54:385-395

32. Breiteneder-Geleff S, Matsui K, Soleiman A, Meraner P, Poczewski H, Kalt R, Schaffner G, Kerjaschki D (1997) Podoplanin, novel 43$\mathrm{kd}$ membrane protein of glomerular epithelial cells, is downregulated in puromycin nephrosis. Am J Pathol 151:1141-1152

33. Ordóñez NG (2006) Podoplanin: a novel diagnostic immunohistochemical marker. Adv Anat Pathol 13:83-88

34. Kahn HJ, Bailey D, Marks A (2002) Monoclonal antibody D2-40, a new marker of lymphatic endothelium, reacts with Kaposi's sarcoma and a subset of angiosarcomas. Mod Pathol 15:434-440

35. Wigle JT, Harvey N, Detmar M, Lagutina I, Grosveld G, Gunn MD, Jackson DG, Oliver G (2002) An essential role for Prox1 in the induction of the lymphatic endothelial cell phenotype. EMBO J 21:1505-1513

36. Rodriguez-Niedenführ M, Papoutsi M, Christ B, Nicolaides KH, von Kaisenberg CS, Tomarev SI, Wilting J (2001) Prox1 is a marker of ectodermal placodes, endodermal compartments, lymphatic endothelium and lymphangioblasts. Anat Embryol 204:399-406

37. Skog M, Bono P, Lundin M, Lundin J, Louhimo J, Linder N, Petrova TV, Andersson LC, Joensuu H, Alitalo K, Haglund CH (2011) Expression and prognostic value of transcription factor PROX1 in colorectal cancer. Br J Cancer 105:1346-1351

38. Ragusa S, Cheng J, Ivanov KI, Zangger N, Ceteci F, BernierLatmani J, Milatos S, Joseph JM, Tercier S, Bouzourene H, Bosman FT, Letovanec I, Marra G, Gonzalez M, Cammareri P, Sansom OJ, Delorenzi M, Petrova TV (2014) PROX1 promotes metabolic adaptation and fuels outgrowth of Wnt(high) metastatic colon cancer cells. Cell Rep 8:1957-1973

39. Banerji S, Ni J, Wang SX, Clasper S, Su J, Tammi R, Jones M, Jackson DG (1999) LYVE-1, a new homologue of the CD44 glycoprotein, is a lymph-specific receptor for hyaluronan. J Cell Biol 144:789-801

40. Mouta Carreira C, Nasser SM, di Tomaso E, Padera TP, Boucher Y, Tomarev SI, Jain RK (2001) LYVE-1 is not restricted to the lymph vessels: expression in normal liver blood sinusoids and down- 
regulation in human liver cancer and cirrhosis. Cancer Res 61: 8079-8084

41. Pajusola K, Aprelikova O, Korhonen J, Kaipainen A, Pertovaara L, Alitalo R, Alitalo K (1992) FLT4 receptor tyrosine kinase contains seven immunoglobulin-like loops and is expressed in multiple human tissues and cell lines. Cancer Res 52:5738-5743

42. Partanen TA, Alitalo K, Miettinen M (1999) Lack of lymphatic vascular specificity of vascular endothelial growth factor receptor 3 in 185 vascular tumors. Cancer 86:2406-2412

43. Baluk P, McDonald DM (2008) Markers for microscopic imaging of lymphangiogenesis and angiogenesis. Ann NY Acad Sci 1131:112

44. Kholova I et al (2011) Lymphatic vasculature is increased in heart valves, ischaemic and inflamed hearts and in cholesterol-rich and calcified atherosclerotic lesions. Eur J Clin Invest 41:487-497

45. Dieterich LC, Seidel CD, Detmar M (2014) Lymphatic vessels: new targets for the treatment of inflammatory diseases. Angiogenesis 17:359-371

46. Xu H, Edwards J, Banerji S, Prevo R, Jackson DG, Athanasou NA (2003) Distribution of lymphatic vessels in normal and arthritic human synovial tissues. Ann Rheum Dis 62:1227-1229

47. Varricchi G, Granata F, Loffredo S, Genovese A, Marone G (2015) Angiogenesis and lymphangiogenesis in inflammatory skin diseases. J Am Acad Dermatol 73:144-153

48. Alexander JS, Chaitanya GV, Grisham MB, Boktor M (2010) Emerging roles of lymphatics in inflammatory bowel disease. Ann N Y Acad Sci Suppl 1:E75-E85

49. Shi VY, Bao L, Chan LS (2012) Inflammation-driven dermal lymphangiogenesis in atopic dermatitis is associated with $\mathrm{CD} 11 \mathrm{~b}+$ macrophage recruitment and VEGF-C up-regulation in the IL-4-transgenic mouse model. Microcirculation 19:567-579

50. Kerjaschki D, Huttary N, Raab I, Regele H, Bojarski-Nagy K, Bartel G, Kröber SM, Greinix H, Rosenmaier A, Karlhofer F, Wick N, Mazal PR (2006) Lymphatic endothelial progenitor cells contribute to de novo lymphangiogenesis in human renal transplants. Nat Med 12:230-234

51. Nykänen AI, Sandelin H, Krebs R, Keränen MA, Tuuminen R, Kärpänen T, Wu Y, Pytowski B, Koskinen PK, Ylä-Herttuala S, Alitalo K, Lemström KB (2010) Targeting lymphatic vessel activation and CCL21 production by vascular endothelial growth factor receptor3 inhibition has novel immunomodulatory and antiarteriosclerotic effects in cardiac allografts. Circulation 121:1413-1422

52. Kerjaschki D, Regele HM, Moosberger I, Nagy-Bojarski K, Watschinger B, Soleiman A, Birner P, Krieger S, Hovorka A, Silberhumer G, Laakkonen P, Petrova T, Langer B, Raab I (2004) Lymphatic neoangiogenesis in human kidney transplants is associated with immunologically active lymphocytic infiltrates. J Am Soc Nephrol 15:603-612

53. Vuorio T, Nurmi H, Moulton K, Kurkipuro J, Robciuc MR, Ohman M, Heinonen SE, Samaranayake H, Heikura T, Alitalo K, YläHerttuala S (2014) Lymphatic vessel insufficiency in hypercholesterolemic mice alters lipoprotein levels and promotes atherogenesis. Arterioscler Thromb Vasc Biol 34:1162-1170

54. Martel C, Li W, Fulp B, Platt AM, Gautier EL, Westerterp M, Bittman R, Tall AR, Chen SH, Thomas MJ, Kreisel D, Swartz MA, Sorci-Thomas MG, Randolph GJ (2013) Lymphatic vasculature mediates macrophage reverse cholesterol transport in mice. $\mathrm{J}$ Clin Invest 123:1571-1579

55. Wassef M, Blei F, Adams D et al (2015) Vascular anomalies classification: recommendations from the International Society for the Study of Vascular Anomalies. Pediatrics 136:e203-e214

56. Greene AK, Liu AS, Mulliken JB, Chalache K, Fishman SJ (2011) Vascular anomalies in 5,621 patients: guidelines for referral. J Pediatr Surg 46:1784-1789

57. Garzon MC, Huang JT, Enjolras O, Frieden IJ (2007) Vascular malformations: part I. J Am Acad Dermatol 56:353-370
58. Richter GT, Friedman AB (2012) Hemangiomas and vascular malformations: current theory and management. Int J Pediatr 2012:645678

59. Folpe AL, Veikkola T, Valtola R, Weiss SW (2000) Vascular endothelial growth factor receptor-3 (VEGFR-3): a marker of vascular tumors with presumed lymphatic differentiation, including Kaposi's sarcoma, kaposiform and Dabska-type hemangioendotheliomas, and a subset of angiosarcomas. Mod Pathol 13:180-185

60. Castro EC, Galambos C (2009) Prox-1 and VEGFR3 antibodies are superior to D2-40 in identifying endothelial cells of lymphatic malformations-a proposal of a new immunohistochemical panel to differentiate lymphatic from other vascular malformations. Pediatr Dev Pathol 12:187-194

61. Meijer-Jorna LB, Breugem CC, de Boer OJ, Ploegmakers JP, van der Horst CM, van der Wal AC (2009) Presence of a distinct neural component in congenital vascular malformations relates to the histological type and location of the lesion. Hum Pathol 40:1467-1473

62. Meijer-Jorna LB, van der Loos CM, de Boer OJ, Horrevoets AJ, Mekkes JR, van der Horst CM, van der Wal AC (2013) Microvascular proliferations in arteriovenous malformations relate to high-flow characteristics, inflammation, and previous therapeutic embolization of the lesion. J Am Acad Dermatol 68:638-646

63. Weiss SW, Enzinger FM (1986) Spindle cell hemangioendothelioma. A low-grade angiosarcoma resembling a cavernous hemangioma and Kaposi's sarcoma. Am J Surg Pathol 10:521-530

64. Wang L, Gao T, Wang G (2014) Expression of Prox, 1, D2-40, and WT1 in spindle cell hemangioma. J Cutan Pathol 41:447-450

65. North PE, Kahn T, Cordisco MR, Dadras SS, Detmar M, Frieden IJ (2004) Multifocal lymphangio-endotheliomatosis with thrombocytopenia: a newly recognized clinicopathological entity. Arch Dermatol 140:599-606

66. Zukerberg LR, Nickoloff BJ, Weiss SW (1993) Kaposiform hemangioendothelioma of infancy and childhood. An aggressive neoplasm associated with Kasabach-Merritt syndrome and lymphangiomatosis. Am J Surg Pathol 17:321-328

67. Miettinen M, Wang ZF (2012) Prox 1 transcription factor as a marker for vascular tumors-evaluation of 314 vascular endothelial and 1086 nonvascular tumors. Am J Surg Pathol 36:351-359

68. Dimaio TA, Lagunoff MKSHV (2012) Induction of angiogenic and lymphangiogenic phenotypes. Front Microbiol 3:102

69. Gutierrez KD, Morris VA, Wu D, Barcy S, Lagunoff M (2013) Ets1 is required for the activation of VEGFR3 during latent Kaposi's sarcoma-associated herpesvirus infection of endothelial cells. J Virol 87:6758-6768

70. Mankey CC, McHugh JB, Thomas DG, Lucas DR (2010) Can lymphangiosarcoma be resurrected? A clinicopathological and immunohistochemical study of lymphatic differentiation in 49 angiosarcomas. Histopathology 56:364-371

71. Willis RA (1960) Pathology of tumours, 3rd edn. Butterworths, London

72. Alexander-Sefre F, Singh N, Ayhan A et al (2003) Detection of tumour lymphovascular space invasion using dual cytokeratin and CD31 immunohistochemistry. J Clin Pathol 56:786-788

73. Vass DG, Ainsworth R, Anderson JH et al (2004) The value of an elastic tissue stain in detecting venous invasion in colorectal cancer. J Clin Pathol 57:769-772

74. Pawlik TM, Delman KA, Vauthey J-N et al (2005) Tumour size predicts vascular invasion and histopathological grade: implications for the selection of surgical treatment for hepatocellular carcinoma. Liver Transpl 11:1086-1092

75. Chen JWC, Bhandari M, Astill DS et al (2010) Predicting patient survival after pancreaticoduondectomy for malignancy: histopathological criteria based on perineural infiltration and lymphovascular invasion. HPB 12:101-108 
76. Storr SJ, Safuan S, Mitra A et al (2012) Objective assessment of blood and lymphatic vessel invasion and association with macrophage infiltration in cutaneous melanoma. Mod Pathol 25:493-504

77. Kirsch R, Messenger DE, Riddell RH (2013) Venous invasion in colorectal cancer: impact of an elastin stain on detection and interobserver agreement among gastrointestinal and nongastrointestinal pathologists. Am J Surg Pathol 37:200-210

78. Gujam FJA, Going JJ, Edwards J et al (2014) The role of lymphatic and blood vessel invasion in predicting survival and methods of detection in patients with primary operable breast cancer. Crit Rev Oncol Hematol 89:231-241

79. Castonguay MC, Li-Chang HH, Driman DK (2014) Venous invasion in oesophageal adenocarcinoma: enhanced detection using elastic stain and association with adverse histological features and clinical outcomes. Histopathology 64:693-700

80. Rose AE, Christos PJ, Lackaye D, Shapiro RL, Berman R, Mazumdar M, Kamino H, Osman I, Darvishian F (2011) Clinical relevance of detection of lymphovascular invasion in primary melanoma using endothelial markers D2-40 and CD34. Am J Surg Pathol 35:1441-1449

81. Van den Eynden GG, Van der Auwera I, Van Laere SJ et al (2006) Distinguishing blood and lymph vessel invasion in breast cancer: a prospective immunohistochemical study. Br J Cancer 94:1643-1649

82. Theunissen PH, Borchard F, Poortvliet DC (1991) Histopathological evaluation of oesophageal carcinoma: the significance of venous invasion. Br J Surg 78:930-932

83. 76. Mapstone NP (2014) Dataset for the histopathological reporting of oesophageal carcinoma (2nd edition). Cancer datasets and tissue pathways. The Royal College of Pathologists. www.rcpath.org
84. Dicken BJ, Graham K, Hamilton SM et al (2006) Lymphovascular invasion is associated with poor survival in gastric cancer. Ann Surg 243:64-73

85. Kooby DA, Suriawinata A, Klimstra DS et al (2003) Biologic predictors of survival in node-negative gastric cancer. Ann Surg 237: $828-835$

86. Liu C, Zhang R, Lu Y et al (2010) Prognostic role of lymphatic vessel invasion in early gastric cancer: a retrospective study of 188 cases. Surg Oncol 19:4-10

87. Loughrey MB (2014) Dataset for colorectal cancer histopathology reports. 3rd edition. Cancer datasets and tissue pathways. The Royal College of Pathologists. www.rcpath.org

88. Minsky BD, Mies C, Rich TA, Recht A (1989) Lymphatic vessel invasion is an independent prognostic factor for survival in colorectal cancer. Int J Radiat Oncol Biol Phys 17:311-318

89. Betge J, Pollheimer MJ, Lindtner RA et al (2012) Intramural and extramural vascular invasion in colorectal cancer: prognostic significance and quality of pathology reporting. Cancer 118:628-638

90. Kojima M, Shimazaki H, Iwaya K et al (2013) Pathological diagnostic criterion of blood and lymphatic vessel invasion in colorectal cancer: a framework for developing an objective pathological diagnostic system using the Delphi method, from the Pathology Working Group of the Japanese Society for Cancer of the Colon and Rectum. J Clin Pathol 66:551-558

91. Sternberg A, Mizrahi A, Amar M, Groisman G (2006) Detection of venous invasion in surgical specimens of colorectal carcinoma: the efficacy of various types of tissue blocks. J Clin Pathol 59:207-210 